\title{
Primeiras comunidades cristãs sob o olhar da Hermenêutica dos Espaços
}

\section{Christian primitive communities from the view of the Hermeneutics of Places}

\section{Las primeras comunidades cristianas desde la pers- pectiva de la Hermenéutica del Espacio}

\author{
Prof. Dra. Danielle Lucy \\ Bósio Frederico* \\ Submetido em: 26-3-2021 \\ Aceito em: 10-5-2021
}

\author{
Universidade Metodista de São Paulo \\ Doutora em Ciências da Religião pela \\ Universidade Metodista de São Paulo \\ (Umesp) \\ danielle.frederico@metodista.br
}

\section{RESUMO}

As comunidades primitivas realizavam os seus encontros comunitários em casas e isso é um fato. Outro fato é que não é incomum imaginarmos as casas do primeiro século como as que residimos hoje. Essa maneira de entendermos os fatos é um anacronismo, pois está fora do tempo, isto é, uma leitura descontextualizada. Uma pergunta simples deveria ser feita ao lermos e/ou pensarmos sobre esse tema: em que tipo de casas eles se reuniam? Como eram as casas daquela época? Haviam outros lugares em que esses cristãos poderiam se reunir? Partindo do pressuposto de que haviam vários espaços nesse mundo antigo que seriam propícios aos encontros dessas comunidades e de que é preciso ampliar a nossa percepção sobre o tema a fim de que novas possiblidades surjam; utilizaremos a Hermenêutica dos Espaços e revistaremos alguns lugares. Nosso objetivo é identificar novas possiblidades e reconhecer a fluidez desse mundo outro e tão rico em que nasceram as primeiras comunidades cristãs. Palavras-chave: Casa; hermenêutica dos espaços; Paulo; domus; ínsula.

\begin{abstract}
Primitive communities held their community meetings in homes and that is a fact. Another fact is that it is not uncommon, it is to imagine the houses of the first century as the ones we live in today. This way of understanding the facts is called anachronism, because it is out of time, that is, a decontextualized reading. A simple question should be asked when reading and / or thinking about this topic: what kind of houses did they meet in? What were the houses of that time like? Were there any other places where these Christians could meet? Starting from the assumption that there were several spaces in this ancient world that would be conducive to the meetings of these communities and that it is necessary to expand our perception on the subject in order for new possibilities to arise; we will use the Hermeneutics of Spaces and search some places. Our goal is to identify new possibilities and recognize the fluidity of this other and so rich world in which the first Christian communities were born. Keyword: House; hermeneutics of places; Paulo; domus; insula.
\end{abstract}

\section{RESUMEN}

Las comunidades primitivas celebraban sus reuniones comunitarias en los hogares y eso es un hecho. Otro dato es que no es infrecuente, es imaginar las casas del siglo I como las que vivimos hoy. A esta forma de entender los hechos se le llama anacronismo, porque es fuera de tiempo, es decir, una lectura descontextualizada. Al leer y / o pensar sobre este tema, se debe hacer una pregunta simple: ¿en qué tipo de casas se reunieron? ¿Cómo eran las casas 
de esa época? ¿Había otros lugares donde estos cristianos pudieran reunirse? Partiendo del supuesto de que en este mundo antiguo existían varios espacios propicios para los encuentros de estas comunidades y que es necesario ampliar nuestra percepción sobre el tema para que surjan nuevas posibilidades; Usaremos la Hermenéutica de los Espacios y buscaremos algunos lugares. Nuestro objetivo es identificar nuevas posibilidades y reconocer la fluidez de este otro y tan rico mundo en el que nacieron las primeras comunidades cristianas.

Palabras clave: Casa; hermenéutica de los espacios; Paulo; domus; insula.

\section{Introdução}

Quando estamos no mundo dos textos bíblicos, faz-se necessário perceber em quais espaços as narrativas acontecem e/ou podem estar acontecendo. Por exemplo, quando dizemos que as comunidades se reuniam em casas, faz-se necessário perguntar: quais casas? Como eram as casas daquela época? Essas perguntas são pertinentes, pois existia a casa do rico - domus; e a casa do pobre - ínsula; e estas tinham, além de dimensões diferentes, uma estrutura totalmente diversa das casas que conhecemos nos dias atuais. Não devemos pensar nas casas desse período no modelo das casas em que vivemos, com divisões e particularidades. Pensar dessa forma é um equívoco que pode nos levar a hermenêuticas e propostas equivocadas, além de limitar as possibilidades no que se refere aos locais em que os cristãos e cristãs daquela época podiam se reunir. A palavra "casa" é carregada de significado cultural, devido às variadas formas, espaços e possiblidades nas quais se incluem o país, o período e a classe social. Por isso, entendemos ser interessante observar os espaços do mundo antigo a fim de resignificar e/ou mesmo perceber uma fluidez maior com relação aos locais de possíveis encontros dos cristãos e cristãs do primeiro século. Para esta análise, utilizaremos a comunidade cristã estabelecida em Corinto como exemplo, aplicando a proposta da Hermenêutica dos Espaços, que passamos a explicar mais detalhadamente a seguir.

\section{Hermenêutica dos espaços}

Reconhecemos que os espaços na antiguidade eram locais que emitiam mensagens. Dependendo do espaço ocupado, uma mensagem era emitida, podendo influenciar de modo significativo o entendimento da narrativa bíblica. Toda narrativa é construída dentro de um espaço ou todo espaço comporta uma narrativa, seja de forma real ou imaginária. Fato é que, na elaboração de narrativas, os autores e/ou escritores estruturam uma cena e essa se encontra localizada em um espaço determinado.

Quando estamos no ambiente da cidade antiga, no que tange à sua arquitetura, à organização das ruas, ao centro comercial, à periferia, às residências 
da elite (GATES, 2011), encontramo-nos em um ambiente estruturado de forma a reproduzir a sociedade que o produziu, isto é, o espaço da pólis é um espaço planejado que sinaliza as estruturas estabelecidas daquele local. Com relação à Antiguidade, temos uma linguagem universal que se refere à estruturação da pólis, mas também distinta, quando se trata, por exemplo, dos espaços de refeição.

A pólis conta com uma arquitetura denominada "Monumentalidade", uma forma de alta visibilidade e durabilidade que tinha como princípio a demonstração de poder e continuidade (HIRATA, 2009). Se seguirmos observando os espaços da refeição, que possuem dimensões menores, perceberemos toda uma elaboração e preparação por parte do anfitrião ao receber seus convidados. Esse local poderia se situar tanto no espaço público como no doméstico. Cada espaço tinha uma hierarquia de poder estabelecida, bem como dinâmicas extáticas com respeito aos relacionamentos e regras da sociedade em que se encontrava. Portanto, o espaço que se ocupava possuía significados diferentes, os quais, acrescidos de uma narrativa, podiam alterar significativamente o entendimento de um texto.

Podemos observar tais convergências quando dos grandes festivais, seguidos de procissões que se deslocam pelas ruas centrais da pólis e terminam em grandes templos, que possuíam um espaço de refeição onde a partilha de uma parte da carne sacrificada era realizada. O que dizer de funerais de pessoas eminentes e de banquetes públicos, quando aconteciam grandes vitórias e conquistas por parte do Império? A "Monumentalidade" expressava e comunicava um poder maior, ou mesmo o poder estabelecido na sociedade em que se vivia. Observamos essa característica também no espaço da refeição, como por exemplo na domus romana - espaço da casa de uma pessoa de alto estrato social, que contava com um local específico no qual se realizava a principal refeição do dia, com convidados e alimentos distintos, os quais tendem a demonstrar a superioridade e, consequentemente, o poder do anfitrião. O caminho que um convidado percorria até chegar ao local em que a refeição iria acontecer, por exemplo, geralmente guiava o comensal por toda a casa, fazendo com que a mensagem implícita fosse veiculada e marcada no convidado. Não havia necessidade de palavras, pois o próprio espaço discursava sobre as características do pater familias ou anfitrião dono daquele espaço e das pessoas e de tudo que compunha o mesmo.

Quando colocamos o espaço da domus romana (casa do rico) em relação com a ínsula (casa do pobre), os tamanhos são absurdamente diferentes e o alimento ingerido segue a mesma lógica. No segundo ambiente, os espaços são menores, por vezes constituídos apenas de um cômodo, as refeições eram realizadas nas ruas e a dieta era constituída de pão, vinho e 
mingau, na maioria das vezes. O poder visualizado na domus era o oposto na ínsula - pequena, escura e perigosa de se morar, dada a falta de estrutura e planejamento. Assim, os espaços nos sinalizam mensagens próprias e específicas! Dito isso, como visualizaríamos o espaço ou os espaços em que uma comunidade cristã se reunia? O que esse espaço poderia indicar sobre a própria comunidade?

Se tomarmos como exemplo a comunidade cristã primitiva de Corinto, uma proposta bem conhecida e difundida é de que suas reuniões aconteciam em uma domus romana (THEISSEN, 1982; O'CONNOR, 2002). Mas as comunidades cristãs eram compostas majoritariamente por pessoas empobrecidas, do estrato baixo da sociedade (FRIESEN, 2005). Então, seria mesmo somente no espaço da domus romana que essas refeições aconteceriam? A comunidade poderia ocupar, alugar e/ou se encontrar em outros espaços que identificariam melhor a sua proposta e identidade cristã em formação?

$\mathrm{Na}$ Hermenêutica dos Espaços, procuraremos partir do espaço para a narrativa; isto é, observar se o relato se encontra em espaço público ou privado, religioso ou não, do alto ou do baixo estrato social, quais são as personagens presentes e o que elas estão representando nesse espaço, etc.

O espaço se constituiria no contexto específico frente à narrativa, pois seria um veículo direcionador da mensagem estabelecida ou da mensagem que se deseja estabelecer. Seria uma mudança de foco, na qual se observaria, em primeiro lugar, o espaço elaborado e/ou construído, as personagens presentes, o mobiliário, a dinâmica relacional existente e, a partir dessas informações, partiríamos para a construção e/ou entendimento da narrativa. Entendemos que, ao realizar tal "inversão", poderemos perceber novas hermenêuticas e fazer novas descobertas no ambiente elencado, pois identificaremos espaços como microcosmos sociais.

\section{A cidade antiga e seus espaços}

Ao observarmos construções e espaços antigos, não devemos, como já foi dito, partir de pressupostos atuais, os quais podem nos levar a anacronismos e, consequentemente, a impressões equivocadas pois, como todos vivemos em um período determinado na história, estamos envolvidos por culturas e discursos que se intercambiam e moldam nossos olhares e percepções.

Tal fato exige de nós uma descentralização do olhar, que seria a observação de um espaço e/ou a percepção do ambiente em que determinados indivíduos, ações, discursos ou eventos estão ocorrendo. Para tanto, é preciso buscar novas concepções e/ou ferramentas de possíveis significados desses espaços e lugares ocupados e/ou construídos nesse mundo antigo. 
Ao pensarmos numa cidade antiga, devemos indagar sobre sua estrutura, seu planejamento, sobre o tipo de mensagem que sua arquitetura e os espaços construídos transmitiam etc. Pois há um ideal - ou ideais - implícito em suas construções, do qual precisamos estar conscientes, a fim de que consigamos discernir o máximo de suas intenções e mensagens.

\section{Espaço como construção social}

Quando estamos no ambiente das cidades, a sua arquitetura, a organização das ruas, o centro comercial, a periferia, o local em que as residências se encontram e etc., nos indicam que tipo de sociedade está presente ali, pois os espaços são construídos e delimitados como um espaço existencial, isto é, espaços que nos falam sobre a sociedade que os produziu.

Partindo desse princípio, a arquitetura pode ser existencial e, como tal, indica o espaço como

[...] uma arena na qual a vida social e individual se desenrola e, ao mesmo tempo, um meio pelo qual as relações sociais são produzidas e reproduzidas. Essa noção é construída socialmente por meio da observação de como as coisas e as pessoas podem ser arranjadas espacialmente. (HIRATA, 2011, p. 10).

Uma dessas expressões é a chamada Monumentalidade, característica presente na arquitetura de uma cidade antiga e que, quase sempre, incorpora e impõe uma mensagem. A arquitetura monumental é uma forma "de alta visibilidade e durabilidade a comunicar um tipo de consumo 'extraordinário' associando-o a um governante ou a uma camada hegemônica detentora do poder" (HIRATA, 2009, p. 122).

A arquitetura monumental é uma forma de comunicar e manter o poder estabelecido, pois integra as estratégias de afirmação do poder em sociedades estratificadas, transmitindo uma ideologia e/ou ideologias através das quais alguns grupos "mantêm, resistem ou mudam ativamente seu poder relativo dentro da sociedade" (KNAPP, 1996 apud HIRATA, 2009, p. 16).

Essas construções possuíam uma alta durabilidade. Portanto, a mensagem transmitida tinha o objetivo de perpetuação de um poder por um longo período de tempo. A necessidade de afirmação desse poder é especialmente encontrada em sociedades altamente estratificadas, conforme Trigger, o qual ainda nos diz que: "a arquitetura monumental e os objetos de prestígio simbolizam a habilidade e a força daqueles que controlam a mão de obra" (TRIGGER, 1990 apud HIRATA, 2009, p. 109). 
Mensagens eram enviadas nos variados espaços da cidade, tendo, em sua maioria, o patrocínio de um patrono na construção de templos, monumentos, mausoléus funerários etc., em busca de honra, visibilidade e manutenção do status. Essa prática também era realizada por alguns clientes bem-sucedidos, que desejavam a manutenção do relacionamento patronal e/ou melhores oportunidades na sociedade.

Florenzano, ao tratar do tema do ambiente, explicita-nos bem essa dinâmica entre espaço - poder - mensagem, ao afirmar que

[...] o ambiente construído é, pois, uma manifestação cultural onde se materializam os traços organizacionais de uma sociedade, assim como os seus aspectos cognitivos e ainda Rapoport quando afirma que "O ambiente físico proporciona pistas para que a pessoa entenda rapidamente qual é a sua situação social”. (RAPOPORT apud HIRATA, 2009, p. 139).

Quando estudamos um grupo urbano, tal como a comunidade cristã de Corinto no primeiro século, a atenção aos espaços se faz necessária, pois, além de seguirem o mesmo princípio da monumentalidade, principalmente em se tratando da domus romana, se constitui em pistas que poderão auxiliar no encontro de melhores hermenêuticas. Através da literatura, sabemos que as comunidades cristãs primitivas se reuniam para partilha de refeições, rito eucarístico, adoração e catequese. Não sabemos ao certo quantas vezes esses grupos se encontravam ou mesmo quantas vezes o rito eucarístico era realizado. Em At 20.7 e em 1Co 16.2, vemos a indicação do primeiro dia da semana, mas, provavelmente, com objetivos diferentes. A primeira referência diz respeito ao encontro da comunidade com o apóstolo Paulo, quando haveria o rito eucarístico e provavelmente a catequese. A segunda referência sinaliza uma coleta (provavelmente para os cristãos de Jerusalém), mas não é indicado quando e onde a mesma aconteceria. Com relação ao local, a literatura nos informa a respeito das reuniões nas casas, na oikos de membros da comunidade cristã ou de amigos e simpatizantes que ofereciam locais para que a comunidade se reunisse ( $\mathrm{Rm}$ 16; 1Co 1.14-16; 1Co 16.19). $\mathrm{O}$ entendimento da casa como ambiente de encontro das primeiras comunidades cristãs é consenso entre os pesquisadores e pesquisadoras:

O modelo do domicílio é o modelo prevalecente na formação eclesial primitiva, a casa era entendida como extensão do corpo social que incluía não somente membros imediatos da família, mas, também, escravos, libertos e outros dependentes - provia o núcleo de uma congregação, enquanto a casa material provia o lugar de encontro congregacional. A casa é, portanto, entendida para ser "o contexto básico" no qual as igrejas primitivas foram estabelecidas, dando forma à sua identidade (como casas ou 
famílias da fé), fornecendo a sua estrutura de liderança primária (na forma de chefes de casa [household heads]), e possibilitando a participação ativa de mulheres na vida eclesial .(ADAMS, 2016, p. 2).

A casa, portanto, seria como uma extensão da sociedade em que se encontrava a família. Quando falamos de uma família romana, não estamos nos referindo apenas ao pater e a mater familias e seus filhos, mas também aos escravos e aqueles ligados à casa, tal como os clientes e libertos. $\mathrm{Na}$ proposta de Wallace-Hadril, que se utiliza do conceito "casa cheia", todos os envolvidos com a domus (casa do alto estrato) fariam parte da família, uma vez que eram corresponsáveis pela manutenção da mesma. Para tanto, a domus deveria ser concebida como um centro de atividades que conciliava o doméstico, os negócios, bem como a espiritualidade. Há uma pluralidade presente no ambiente interno da casa que indica tanto a sua importância na estrutura da sociedade quanto a centralidade da mesma na formação do indivíduo: 1

[...] a casa não era "privada" como a entendemos. Para nós, o "lar" está fortemente separado do mundo dos negócios e da política; é aonde você vai para escapar das limitações e obrigações da vida pública. Na discussão de Vitrúvio, pelo contrário, domus é tratado como parte da imagem pública do dono e cria o pano de fundo na condução de parte da vida pública (BEARD, 2016, p. 126).

Ainda observando a domus, Beard (2016) se utiliza da classificação de Vitrúvio, que identificava esse tipo de moradia como "casa para exibição", tendo como objetivo ostentar a riqueza de seu proprietário.

O espaço físico da casa refletia essa necessidade de autorrepresentação e propaganda no mundo romano. O que um romano representava na casa dele ou dela não era necessariamente um reflexo de escolha individual. A verdadeira pertença romana tinha a ver com Romanitas, demandava um certo apagamento da característica individual, especialmente se o que caracterizava era a etinicidade, uma prática religiosa ou uma história familiar em desacordo com o modo previsto de pertencimento ao tempo do Império.

Tal pluralidade poderia ser resultado ou reflexo do espaço público ou mesmo da concepção de cidade, a qual foi passando por vários entendimentos, como Kormikiari nos informa: Com relação ao desenvolvimento desse conceito, temos três expoentes: Fustel de Coulanges, que privilegiou os elementos religiosos (final do século XIX); Gordon Childe, que optou pelos econômicos (início do século XX) e, por último, de acordo com a autora, mais recentemente, vemos autores como M A. Levi (1989) que chegaram a conclusões mais sensatas. Esse pesquisador defende que o conceito de cidade "é tão complexo que as causas de sua origem, formação e dissolução não podem ser estudadas sem se levar em consideração que, na História, não existe apenas racionalidade nas premissas e consequências. Ou seja, o modelo de cidade tem que ser reestruturado de acordo com a realidade que se estuda" (Cf. KORMIKIARI, 2009, p. 138). 
(...) Essa identidade romana era refletida através do design arquitetônico, decoração e comportamento apropriado, incluindo convites para a casa (CIANCA, 2018, p. 47).

Assim, os seus interiores eram feitos para serem vistos; por isso as áreas mais visitadas eram as mais mobiliadas. A porta de entrada deveria prover uma visão cuidadosamente planejada de alguns aspectos do espaço interior. $\mathrm{O}$ desenho da casa, portanto, poderia ser relacionado às hierarquias da sociedade romana, tais como o seu interior, composto por duas áreas, "comuns" e "exclusivas". As áreas "comuns" seriam aquelas nas quais os visitantes poderiam transitar sem serem convidados, pois teriam livre acesso: átrios, vestíbulos e peristilos. Já as áreas “exclusivas”, tais como a cubicula (ou "quarto de dormir"), triclínios (salas de jantar) e banhos (quando havia) só eram permitidos para convidados. Tal como a sociedade, a casa do alto estrato estendia a dinâmica binária presente na hierarquia da época.

Branick, refletindo sobre o tema da casa em Paulo, afirma que ele se utilizava de dois termos oikoi e oikia. Essas palavras poderiam ter entendimentos diferentes no grego clássico, a saber: a ideia de riqueza, posses ou um espaço físico - oikooi ; e uma semântica mais relacionada a parentes, serviçais ou mesmo clientes de uma família, para oikia. Ambas as palavras eram usadas para moradia, família ou parentela. O mesmo pesquisador afirma ainda que:

O grego de Paulo, porém, mostra muito mais afinidade com o grego da Setenta, a tradução grega do AT hebraico e aramaico do século II a.C., feita para os judeus de fala grega, como o próprio Paulo. Os tradutores da Setenta precisaram traduzir a palavra hebraica bait, que, às vezes, significava um aposento num edifício (Et 2.3; 7.8); a família inteira, incluindo o pai (Gn 50.8; 1Sm 1.21), a mulher, a concubina, os filhos, filhas (Gn 36.60), empregados dependentes (Gn 13.1), serviçais (Gn 15.2-3), atendentes (Gn 14.14) e escravos $(17.13,27)$; parentes que formavam um grupo entre a família imediata e a tribo (2Sm 9.7); junto com as posses da família, incluindo riquezas, ferramentas, escravos e gado (Êx 20.17; Et 8.1). Sem nenhuma distinção aparente, esses tradutores escolheram tanto oikos como oikia para expressar o amplo conceito de bait. A única diferença percebida entre as duas palavras gregas é a diferença maior do uso da palavra oikos em relação à palavra oikia. Consideradas as raízes helênicas ou judaicas, o conceito de oikos é consideravelmente mais abrangente do que nosso conceito de "família". Também o termo "casa", em nosso vocabulário, não faz justiça à extensão do conceito judaico-helênico. (BRANICK, 1994, p. 36).

Discorrendo sobre esse tema, Adams já afirma que, observando algumas questões do epistolário paulino, há apenas quatro ocorrências da expressão: h kat oikon ( + pronome pessoal) ekelhsia e que essa aparece sempre no momento das despedidas e agradecimentos: 1Co 16.19, quando os agradecimentos são extensivos a Áquila e Priscila juntos. Em Rm 16.3, agradece a 
Priscila e Áquila, que agora estão em Roma; e, no começo, a Filemon (16); por fim, em Cl 4.15. Segundo Adams, o termo oikoi, empregado nessas passagens, poderia se referir a uma unidade social ou a uma habitação material, se propriamente uma casa ou uma habitação mais amplamente. Se oikoi é entendida como se referindo à "casa", a expressão h kat oikon ekklhsia poderia se referir a uma das unidades que compõem a congregação cristã. Não sendo, necessariamente, uma casa. Para isso, ele observa que o local em que os cristãos se reuniam em Éfeso e Roma, sob a liderança de Priscila e Áquila não parece ser a casa deles. Não há indicação de que eles tinham filhos ou escravos. Não há referência à casa de Priscila e Áquila; eles aparecem como um casal de missionários, que tinham como ofício fazer tendas. Suas igrejas eram compostas, possivelmente, por novos convertidos, na casa de Onesíforo (2Tm 4.19). O autor cita O'Connor e Lampe, os quais têm argumentado a possiblidade de que Priscila e Áquila poderiam ter se reunido em Éfeso e em Roma, em "habitações-oficina (taverna)". Eles provavelmente alugavam espaços (oficinas, lojas) dada a mobilidade do casal.

Os termos oikoi e oikia, segundo ele, poderiam ser utilizados de várias formas, indicando somente uma casa ou uma variedade de habitações, ampliando assim as possibilidades. Tal fato é encontrado em Paulo, que alterna o sentido do termo, como, por exemplo, em 1Co 1.16; 16.15. A variedade inclui "arranjos habitacionais" [dwelling arrangement tais como lojas e oficinas. Assim, o termo oikoi, junto com a fórmula h kat oikon ekkllbsia não se refere necessariamente a uma "casa", no sentido de construção utilizada principalmente ou somente para uso doméstico (ADAMS, 2016).

Isso nos faz refletir se, como defendido por O'Connor (2002), a comunidade cristã em Corinto se reunia somente na domus romana. Ao estruturar sua proposta, O'Connor tomou como modelo uma casa tradicional da villa romana de Anaploga. Essa casa seria uma domus romana que comportava vários cômodos, dentre os quais o triclínio, local em que as refeições formais aconteciam. De acordo com ele, no triclínio ficariam acomodadas as pessoas de status superior (09 a 11 pessoas); e aquelas de status inferior ficariam no átrio, onde permaneceriam, provavelmente de pé ou assentados no chão. Sendo assim, tanto a qualidade da comida servida como a distinção hierárquica seriam, novamente, reafirmadas nas reuniões comunitárias.

David G. Horrel discorda da proposta de O'Connor, pois duvida da presença de ricos na comunidade cristã em Corinto. Ele afirma, ainda, que o edifício de dois andares localizado na rua do teatro em Corinto seria um possível espaço para a assembleia eucarística, sendo um espaço doméstico indicado para os "sem-elite". A parte térrea dessa construção teria sido uti- 
lizada como comércio e as partes superiores utilizadas como moradia por pequenos comerciantes.

Concordamos com Horrel e Adams, entendendo que essas seriam possiblidades mais plausíveis e coerentes com a dinâmica socioeconômica presente na comunidade cristã de Corinto, uma vez que seus integrantes se constituíam em pessoas simples, que possuíam parcos recursos. Assumimos a proposta de Friesen quanto à possibilidade de que, provavelmente, não houvesse patronos abastados que proveriam um local específico para as reuniões comunitárias, tal como usualmente acontecia nas associações e collegia. O mais provável era uma comunidade de fé que se reunia em espaços domésticos menores, organizada em pequenos grupos de fiéis. Quando e se houvesse necessidade de uma reunião com a presença de todos os integrantes, temos duas indagações: quantos membros as comunidades cristãs possuíam? Por que não pensar que os integrantes da comunidade cristã, quando precisassem de um local mais amplo, não poderiam unir esforços, de modo que cada um doaria um valor; alguém que conhecesse o proprietário de um local pudesse conversar e conseguir um preço mais acessível e/ou mesmo sublocar um local? Tal proposta pode parecer anacronismo, mas sabemos que a solidariedade entre pessoas empobrecidas é um fato presente em todas as épocas.

Discorrendo sobre a possibilidade do aluguel de salas de jantar na antiguidade, Adams (2016) nos informa que o aluguel desses espaços era algo comum, realizado por associações e pequenos grupos. $\mathrm{O}$ valor poderia ser rateado entre os membros ou mesmo pago por um anfitrião, o qual poderia cobrir também os custos com a comida e o aluguel da sala para o jantar. Comunidades carentes fazem os mais variados esforços para alcançarem seus objetivos. Por que pensar uma comunidade cristã primitiva de forma diferente?

Com relação ao número de fiéis da comunidade cristã em Corinto, O’Connor estima algo em torno de 30 a 40 pessoas. Entendemos ser um número plausível, tendo em vista a composição das famílias, mas esta estimativa também poderia variar para menos, por que não?

Provavelmente, as primeiras comunidades cristãs tenham sido compostas por um pequeno número de integrantes, dada a sua marginalidade e adoração de uma nova divindade. Havia uma abertura para novos cultos e divindades, mas não sabemos quanto tempo era necessário para que uma divindade se tornasse popular. O que Mary Beard fala sobre os deuses na cidade de Pompéia é bastante pertinente:

Ninguém debatia, como fazemos hoje, se haveria um poder divino no mundo. O ateísmo não teria sido entendido como uma posição intelectual ou religiosa. De fato, à parte de judeus e cristãos, a ideia da existência de um só deus, em vez de muitos, teria soado 
excêntrica no século I, ainda que mais tarde tenha se tornado comum, mesmo entre os pagãos. Mas isto não significa que o antigo politeísmo estivesse isento de disputas e controvérsias. Os romanos podiam discordar violentamente, não a respeito da existência dos deuses (isto era um fato, e não uma crença), mas sobre como eram e como as diversas deidades se relacionavam entre si e como, quando e por que intervinham nas vidas dos humanos. Era perfeitamente possível imaginar, por exemplo, se os deuses realmente tinham forma humana (ou exatamente o quão semelhante aos humanos seriam), ou se eles se preocupavam de fato com as vidas dos humanos. Como eles se revelavam às pessoas? Quão caprichosos ou benevolentes seriam? Seriam amigos ou sempre inimigos em potencial? (BEARD, 2016, p. 322-323).

Como uma religião "excêntrica", formatada no ambiente doméstico, poderia se estruturar e se distinguir frente a tantas outras expressões religiosas? Jenn Cianca (2018) apresenta a tese de que isso se daria de forma plural, através de uma combinação de fatores em que nada seria rejeitado e, sim, intercambiado. Para ela, o cristianismo primitivo, ao se desenvolver em ambientes domésticos, também tomou parte do culto doméstico às divindades ali veneradas, presente em todas as casas e espaços da antiguidade. A prática do culto doméstico era vista como Romanitas, isto é, a identidade daquela família, em especial do pater familias como parte do Império Romano. Ao exercer o seu sacerdócio no lar junto à família, o pater indicava a sua fidelidade ao governo instituído, demonstrava a sua piedade (algo de muito valor na época), dava continuidade aos valores sociais e familiares, uma vez que as divindades adoradas, os antepassados, as orações e a liturgia do culto deveriam ser ensinados ao filho, para que esse perpetuasse tudo junto às próximas gerações. Tais procedimentos também auxiliavam na manutenção da pax deorum e, consequentemente, todas essas ações trariam honra àquela casa. Cianca defende que o culto cristão seria realizado dentro dessa mesma casa, mas tendo um espaço diferente, tendo em vista sua concepção de espaço sagrado temporário e não-permanente, como entendidos em espaços construídos especificamente para a adoração a uma divindade, tal como os templos. Esse espaço sagrado temporário poderia ser multivalente ou polissêmico, pois se estabeleceria durante a performance ritual, não exigindo que a rotina da casa fosse alterada. Assim, "as fronteiras temporariamente estruturadas do espaço sagrado na casa-igreja ${ }^{2}$ poderiam permitir tanto a produção do espaço ritual cristão como a continuação da vida doméstica romana, incluindo a prática do culto doméstico" (2018, p. 170). Dessa forma,

\footnotetext{
2 A expressão 'casa-igreja' utilizada pela pesquisadora é definida por ela como "algo não alterado, espaço de moradia habitado, usado pelos cristãos para adoração, incluindo não somente casas, mas apartamentos, lojas e espaços partilhados em 'cortiços' e espaços rurais ou fazendas” (Cf. CIANCA, 2018, p. 6).
} 
a criação do espaço sagrado no espaço doméstico não precisaria de altares, salas ou quaisquer instrumentos (ou mesmo a remoção de algo), visto que o mesmo seria temporariamente criado durante a performance ritual dos membros envolvidos, reunidos para um propósito específico em um determinado período de tempo. Haveria, segundo ela, um constante processo de negociação, pois esse espaço sagrado não demandava negação ou rejeição das práticas tradicionais do culto doméstico.

A proposta da pesquisadora apresenta uma lógica condizente com o mundo plural da antiguidade, principalmente no que se refere à característica do processo de constante negociação, pois espaços sagrados construídos especificamente para a adoração cristã serão construídos e/ou organizados somente no período de Constantino.

Quais seriam os espaços que os cristãos primitivos poderiam ter utilizado para seus encontros? O espaço cristão no ambiente doméstico se faz necessário também para a construção identitária do grupo, pois o ambiente comunica identidade e status, tal como vimos anteriormente na fala de Beard sobre Vitrúvio, com relação à domus romana como "casa de exibição". A partir do momento que as reuniões cristãs acontecem em outros ambientes, o espaço sagrado temporário é estabelecido, os participantes leem o ambiente, identificam o contexto e agem de acordo. Essa ideia, segundo Rapoport, ${ }^{3}$ agrega-se a uma das possíveis definições de cultura: fenômeno que existiria para permitir às pessoas coagirem por meio de noções compartilhadas de comportamento aceitável:

Por ser produto direto da atividade humana e, mais especificamente, de um determinado agrupamento social, o jogo entre ambiente construído e as pessoas que o produziram revela quais pressupostos entraram em ação ao longo da produção de um determinado ambiente. [...] Uma vez estruturado, o ambiente construído induz comportamentos. A localização de portas e corredores, por exemplo, estabelece o grau de acessibilidade de um indivíduo a um determinado ambiente; ou então, a existência ou não de janelas determina o grau de exposição de um ambiente [...] o espaço é mnemônico, lembra o agente como agir. É o que os estudiosos denominam comunicação visual. (KOMIKIARI, 2009, p. 141).

Assim, reuniões cristãs em ambientes que não sejam especificamente uma domus romana proporcionariam uma acessibilidade muito maior, bem como construiriam um ambiente mais inclusivo e de possibilidades, dada a presença

\footnotetext{
Amos Rapoport, arquiteto norte-americano, é responsável pelo desenvolvimento do conceito "ambiente construído”, em 1982. Para ele, existem questões básicas nos estudos que relacionam o homem e seu meio ambiente. A mais importante delas trata do efeito do meio ambiente no comportamento humano, o qual teria efeitos diretos e indiretos (cf. KORMIKIARI, 2009, p. 138).
} 
de escravos, libertos, mulheres e crianças. A presença de não-cristãos também seria facilitada, dependendo do lugar em que o ritual eucarístico ou as reuniões viessem a acontecer. Mas é muito interessante a observação de Cícero:

A verdade é que a dignidade de um homem pode ser aumentada pela casa em que ele mora, mas não totalmente garantida por ele; o dono deve trazer honra para a casa dele, não a casa para o dono dele. Na casa de um homem distinto, no qual numerosos convidados devem ser entretidos e multidões de todo tipo de pessoas recebidas, cuidado deve ser tomado para tê-lo espaçoso. Mas se não é frequentado por visitantes, se tem um ar de solidão, um palácio espaçoso muitas vezes se torna um descrédito para seu dono. Este é certamente o caso se, em algum outro momento, quando tinha um dono diferente, ele costumava estar lotado. Pois é desagradável, quando os transeuntes comentam: "Ó boa casa velha, ai! Quão diferente é o dono que agora te possui!". Para quantas pessoas imitam zelosamente as fraquezas dos grandes... Por exemplo, quem copia as virtudes de Lucius Lucullus, homem excelente que ele era? Mas quantos há que copiaram a magnificência de suas moradias! (Cícero, De fi ciis 1.39, LCL) (DICKMANN apud Balck, 2004, p. 33).

A movimentação da casa também se encontrava ligada ao caráter do proprietário. Portanto, no tocante às reuniões cristãs, deveriam ter livre acesso para que, assim, ele fosse bem visto.

\section{Espaços para reuniões e encontros comunitários: possibilidades}

Onde a igreja poderia se reunir? Onde as pessoas mais simples residiam? Esses locais dariam, de fato, mais acessibilidade a não-cristãos? A fim de responder essas questões, utilizaremos exemplos de algumas cidades da Ásia Menor, antiga Anatólia, que detêm sítios bem preservados e/ou reconstruídos, tais como Éfeso e Priene. Também utilizaremos exemplos da cidade de Pompéia, uma vez que se apresenta como o melhor sítio arqueológico preservado, dadas as circunstâncias de sua extinção. Herculano e Ostia também serão sítios citados nesse artigo.

Observando a estrutura de uma cidade antiga, veremos sempre uma rua principal, que corta toda a cidade. Nela serão encontradas lojas, domus (casa de pessoas do alto estrato), templos, provavelmente uma ágora (onde também se desenvolverá o comércio), teatro, fórum, termas ou casas de banho, latrinas, tavernas, prostíbulos, propinae (estabelecimentos comerciais que ofereciam alimento já preparado para o consumo) e bares. Fora da cidade, geralmente na entrada ou na saída, ficava o cemitério. 
Vários pesquisadores e pesquisadores concordam que as reuniões poderiam acontecer em vários tipos de casas: domus, insula e loja (BRANICK, 1994; BALCK, 2004; ADAMS, 2016; CIANCA, 2018). Robert Jewett argumenta que muitos cristãos que moravam em grandes cidades, tais como Roma, teriam residido em insulae - blocos de apartamentos com vários andares, em vez de villas privadas. Ele utiliza a expressão "igrejas apartamentos" ou "igrejas cortiços" [tenement churches] e acredita que

[...] teria sido mais igualitária do que uma "casa igreja" [house church], assim não haveria a dependência de um proprietário rico, e teriam se encontrado em um espaço nos andares mais altos ou em uma das áreas partilhadas do térreo. (ADAMS apud JEWETT, 2016, p. 6).

Geralmente, acima das lojas ${ }^{4}$ havia um espaço onde os comerciantes utilizavam como acomodação ou mesmo residiam com suas famílias. O acesso a esse espaço poderia ser externo ou através de uma escada no interior da loja. Esses locais eram pequenos e, por vezes, com apenas uma pequena janela que trazia certa luminosidade ao local. Essas "lojas residenciais" deveriam ser alugadas, pois, segundo a lei romana, "a propriedade estava ligada ao terreno, então as unidades habitacionais separadas do segundo piso não poderiam ser propriedade de seus ocupantes" (BEARD, 2016).

Dependendo da cidade, as casas das pessoas mais simples poderiam ser encontradas em locais fora do centro, em construções chamadas insulae (bloco de pequenos apartamentos) os quais, dependendo da situação financeira da família, teriam apenas um cômodo. A ideia mais vívida de como seria uma insula se encontra na descrição da cidade de Pompéia:

[...] muitos habitantes da cidade viviam em um só quarto pequeno acima das lojas, bares ou oficinas, sem abastecimento de água "encanada" e, frequentemente, sem calefação e fogão - exceto, talvez, por um pequeno fogareiro (que deveria representar uma séria ameaça de incêndio). Quartos compactos para um só ocupante, este tipo de apartamento devia ser pouco mais do que um dormitório apertado para uma família de três ou quatro. Eles deviam ir às ruas para a maior parte de suas necessidades básicas: água nas fontes públicas, alimentação num dos muitos bares e cafés que se abriam diretamente para as

\footnotetext{
Essas lojas serviam a uma variedade de funções. O mais comum eram as tabernas e macela, mas sapateiros e outros comerciantes também poderiam utilizá-las. Lojas funcionavam como locais de trabalho durante o dia, mas, pela noite, elas eram utilizadas como moradia daqueles que ali trabalhavam e, às vezes, suas famílias inteiras também. (....) Outras lojas não tinham nenhuma articulação com outro espaço entre o trabalho e o espaço de moradia, isto é, um cômodo-loja tinha função dupla - espaço de trabalho e moradia. Mesmo esses locais indicavam uma situação regular a quem tinha o próprio espaço para morar. Muitos dividiam espaço em um único cômodo e pequenos apartamentos com outras famílias (Cf. CIANCA, 2018, p. 45).
} 
calçadas - além de pão, frutas, queijos e qualquer preparado simples que pudesse ser feito nos braseiros. (BEARD, 2016, p. 77).

Esse tipo de construção, por conta das precárias condições do material utilizado em sua estrutura, não sobreviveu ao tempo, aos abalos sísmicos frequentes dessas regiões e aos constantes acidentes que ocorriam, tais como incêndios. Residir em insulae era reconhecidamente perigoso, mas era o tipo de habitação mais comum no contexto urbano. Por vezes, famílias dividiam a mesma insula, dadas as condições financeiras vivenciadas:

[...] O apartamento comum (cenáculo) de uma ínsula era alugado por cerca de quarenta denários por mês. Como o denário era geralmente o salário de um dia de trabalho de trabalhador comum, famílias pobres tinham de se unir e dividir esses pequenos quartos. Contrastando, assim, com uma espaçosa domus no andar térreo da ínsula que poderia ser alugado por cerca de 625 denários por mês. (BRANICK, 1994, p. 41).

Em alguns locais, havia um espaço central comum, pois várias dessas habitações eram anexas à domus ou a uma grande casa localizada no térreo. Nessas construções, os jardins, átrios e peristilos poderiam ser acessíveis aos moradores da insulae. Balck, referindo-se às ricas casas pompeianas, observa que não havia, nessa cidade, nenhum tipo de zoneamento separando ricos e pobres. Para ele, bem como para Wallace-Hadrill, ricos e pobres, senhores e escravos coexistiam nos mesmos espaços domésticos (BALCK, 2004).

Havia também apartamentos mais espaçosos, de tamanhos medianos, que poderiam ter sido alugados por comerciantes bem-sucedidos, mas não aristocratas. Um complexo de apartamentos em Ostia com variados tipos e tamanhos poderia ter sido alugado por romanos de situação financeira mais estável. Esses espaços maiores, tais como em Ostia, tinham alguns aspectos comuns, como um pátio central que provia espaço externo, uma latrina, ou um nicho honrando uma divindade particular, acessível a todos os habitantes desses apartamentos (CIANCA, 2018).

Não era incomum uma domus possuir várias lojas incorporadas, tais como uma insula em Herculano, que possuía dez lojas de frente em uma rua principal e a Casa do Fauno, em Pompeia, que contava com cinco lojas ao longo da parte da frente da casa (BALCK, 2004; ADAMS, 2016). Esse era um fato comum, principalmente se a domus se encontrava em uma rua movimentada. O aluguel de imóveis e dos espaços mais variados, como veremos a seguir, deveria ser mais amplo e sistemático. Dois anúncios para aluguéis foram encontrados em Pompéia: 
[...] Para alugar a partir de $1^{\circ}$ de julho. $\mathrm{Na}$ insula Arriana Polliana, propriedade de Caio Aleio Nigídio Maio, unidades comerciais/residenciais com mezaninos [tabernae cum pergulis suis], apartamentos de qualidade no segundo piso [cenacula equestria] e casas [domus]. Agente: Primo, escravo de Caio Aleio Nigídio Maio.

[...] uma elegante sala de banho para clientes de prestígio, tabernae, acomodações no mezanino (pergulae) e apartamentos no piso superior (cenacula) com contrato de cinco anos. (BEARD, 2016, p. 135 e 137).

Podemos perceber que, se não na domus ou além dela, vários espaços poderiam ser utilizados para a realização da reunião de grupos cristãos. Muitas ações missionárias paulinas poderiam ter acontecido em pequenos comércios, bem como em espaços menores, tais como a insula; e os possíveis espaços compartilhados e/ou acessíveis quando anexos a uma domus ou a uma grande casa. Átrios, jardins e outros espaços poderiam ser utilizados tanto para as reuniões - uma vez que não sabemos o número de integrantes e entendemos que a comunidade cristã se reunia em pequenos grupos.

Os espaços eram multifuncionais e se, como as evidências sugerem, os cristãos primitivos eram geralmente pequenos comerciantes e trabalhadores manuais, como o próprio Paulo, Áquila e Priscila, lojas, oficinas e casas (domus e insulae) poderiam ser locais de encontro, ritual e catequese. Sobre a loja ser identificada como um local para ensino e, quem sabe, discursos intelectuais, Ronald Hock sinaliza que:

[...] lojas e oficinas eram cenários conhecidos para discurso intelectual. Xenofonte mostra Sócrates discutindo filosofia em várias lojas e oficinas, incluindo uma loja de seleiros (a saddler's shop) e um estúdio de pintor e uma oficina do fabricante de corselet (a corselet-maker's workshop). De acordo com Diogenes Laertius, Sócrates frequentemente visitava a oficina de Simão, o sapateiro, e se envolvia em conversas com ele. Simão fez nota de que essas conversas foram os primeiros diálogos escritos de Sócrates. (ADAMS apud HOCK, p. 143).

Logo, nesses espaços também poderiam acontecer a catequese de pequenos grupos e o debate sobre temas variados, enquanto repartiam alguma refeição rápida durante o dia ou mesmo após a participação do ritual eucarístico.

\section{Outros espaços}

\section{Tavernas}

Trata-se de espaços bastante populares no mundo romano: 
[...] a taverna era a forma de arquitetura mais onipresente e dominante em Roma e por todo mundo romano [...] filas de tavernas atrás de colunadas, nas ruas ou ao redor de fóruns e mercados. [...] ruínas de tavernas têm sido encontradas por toda a parte; só em Pompéia 577 estruturas já foram identificadas e em Ostia algo em torno de 806. (ADAMS, 2016, p. 139).

Ela poderia consistir em um espaço com a fachada aberta para a rua, que se encontrava anexada a construções maiores, complexos públicos, termas, domus etc. Algumas possuíam um mezanino conhecido como pérgula, que ficava no nível superior, acessível por uma escada de madeira. Em Pompéia, foi encontrado um pequeno jardim atrás de algumas tavernas.

A taverna possuía balcões de alvenaria de frente para as calçadas, com grandes jarras com vinho (dolia) e estantes ao fundo. São sempre associados a locais voltados à bebedeira, consumo excessivo de comida barata, sexo, prostituição, crimes etc.; mas Beard nos informa que:

[...] a realidade de grande parte da vida nas tavernas era menos escabrosa e mais variada do que sugeriam os escritores e legisladores romanos das classes altas, sempre prontos a considerar moralmente duvidosos os locais de diversão popular (...) os balcões com dolia e estantes certamente para vender alguma coisa, mas talvez se tratasse de uma ampla variedade de produtos e não necessariamente comida e bebida para consumo no local. Em outras palavras, estes bares, na verdade, podiam ser armazéns, ou algo parecido, que vendiam nozes, lentilhas e feijões (2016, p. 264-265).

Axel Boethius cunhou o termo "tavernas-casas", pois, dentre as várias funções, a pérgula também poderia ser utilizada como moradia ao dono da taverna e à sua família, como acomodação, local de descanso; e - por que não? - espaço para o encontro de um pequeno grupo de cristãos.

\section{Pousadas e/ ou estalagens}

Como descrito nos Atos de João 60-61, quando o apóstolo João, junto com seus discípulos, em viagem para Éfeso, para em uma estalagem/hospedagem para descansar. Ao se deitar, João sente percevejos e pulgas e os manda sair do colchão ou da cama e permanecerem na porta. Eles permanecem a porta, sem incomodar o apóstolo, até que esse os autoriza a voltar, visto já ter descansado e estar deixando o local para seguir viagem. Esses locais seriam estabelecimentos para os pertencentes ao baixo estrato. Pessoas comuns, tais como missionários, pregadores itinerantes, comerciantes, mercadores e vendedores, que paravam para descansar por um curto período de tempo ou mesmo pernoitavam, a fim de seguir viagem no dia seguinte. Esses locais 
poderiam ser encontrados em pontos estratégicos, como a entrada de cidades e vilarejos. Pessoas do alto estrato, ao realizarem as suas viagens, poderiam contar com amigos e associações que proviam suas hospedagens, ou mesmo - se suas viagens fossem frequentes pela mesma rota - poderiam manter e/ ou possuir uma casa de destino; provavelmente, já possuíam locais certos para as suas paradas. DeFelice identifica três tipos de estabelecimentos com essas características em Pompéia, a saber:

[...] Hospitium: às vezes também chamado de deversorium (hotel), era uma grande pensão ou hotel, com convidados a curto e longo prazo. Caupona: era uma pousada, que oferecia acomodação, comida e bebida, especialmente para viajantes. Stabulum: era um hotel que poderia também acomodar cavalos e carros, geralmente situada no portão da cidade. (ADAMS apud DeFELICE, 2016, p. 159).

Locais como a taverna recebiam má publicidade, sendo identificados como imundos, infestados de insetos e inseguros. No entanto, essa pode ter sido a descrição não de pessoas comuns, do baixo estrato. Um outro exemplo também pode ser visto no Satyricom, quando Encolpius aluga um local com apenas uma cama e um tipo de mesa. $\mathrm{Na}$ descrição, a comida poderia ser consumida no quarto e deveria ser levada ou ter sido comprada anteriormente. Moradores pobres da cidade também poderiam alugar esses espaços, pagos por semana ou em diárias (ADAMS, 2016).

\section{Casas de banho e outros espaços ao ar livre}

Esses locais eram públicos e frequentados por todos os tipos de pessoas. Tal como um centro social, seria um bom local para reuniões informais de um grupo de cristãos, principalmente se houvesse batismo. Esses estabelecimentos geralmente fechavam ao entardecer e dificilmente seriam utilizados para adoração e culto. Caso fossem utilizados em horários alternativos, manhã ou noite, haveria a necessidade de um arranjo especial com o responsável pelo espaço. Batismos poderiam ser realizados nesses locais quando não houvesse acesso a rios e mares. A boa localização, o espaço fechado e a capacidade de reunir um bom número de pessoas podem ser vistos como possibilidades para que esses encontros pudessem acontecer (ADAMS, 2016).

O mesmo autor propõe, como uma possibilidade, encontros informais dos cristãos em espaços abertos como o Fórum, os portões da cidade, nas ruas e fontes de água. Sobre encontros informais junto às fontes de água encontradas em Pompéia, Beard nos diz que: 
[...] A maioria seguia o mesmo plano geral: um grosso bico por onde corria água ininterruptamente e um tanque para represar parte do fluxo, feito de quatro grandes blocos e pedra vulcânica. Em geral, elas eram construídas nas encruzilhadas e esquinas e algumas ultrapassavam a linha da calçada (...) os que contavam com abastecimento doméstico privado não confiavam neste serviço público, mas os menos afortunados, sim - e em grande número, a julgar pelas superfícies de pedra que foram polidas em ambos os lados pelo uso. (...) Tenham ou não se tornado um centro na organização de associações locais, como sugerem alguns estudiosos, as fontes claramente eram pontos informais de reunião dos moradores mais humildes. (BEARD, 2016, p. 85).

Espaços abertos, ao ar livre, poderiam ser palco de encontros de pequenos grupos de cristãos, conversas informais, ensino e tantas outras coisas que acontecem no dia a dia de uma comunidade de fé. Várias coisas aconteciam no espaço da rua; vejamos o que nos diz Adam:

Nas ruas, poderiam ser encontrados locais pedagógicos. Ensino elementar tomava lugar nas ruas. De acordo com Livio (6.25.8-9), quando Camilo entrou em Tuscullum, ele encontrou "as lojas com suas persianas fechadas e todas as mercadorias expostas, todos os artesãos ocupados em seus respectivos trabalhos, o zumbido das escolas com as vozes dos escolares, multidões na rua". Dio Chrysostom (Or.20.9) conta como "os professores elementares sentados nas ruas com seus pupilos, e nada os impede nesta grande forma de ensinar e aprender". Outro local convencional para o ensino primário era um trivium ou quadrivium, um local onde três ou quatro ruas se encontravam. Nesse local, como nos assinala Bonner, o trivium era dificilmente um lugar de ensino saudável: "esse era um lugar de barulho e alvoroço, onde amigos se encontravam e fofocavam, e arruaceiros argumentavam e trocavam farpas; ele era frequentado por charlatões vendendo seus produtos, parasitas que querem ser convidados, vagabundos, adivinhos, e músicos itinerantes". (BEARD, 2016, p. 190).

Espaços dos mais variados eram disponíveis, adequados e usados em múltiplas atividades. Eles poderiam ser utilizados pelo grupo de fiéis das comunidades primitivas, as quais ainda estavam em formação, talvez contando com um número pequeno de pessoas.

\section{Considerações finais}

Frente ao exposto, precisamos revisitar os espaços do mundo antigo e perceber as inúmeras possiblidades de encontros e/ou locais de reuniões que os primeiros cristãos e cristãs tinham à sua disposição. Perceber novas possiblidades nos auxiliam a reconhecer uma maior flexibilidade, o que nos retira de um lugar único. Novas possiblidades para os locais dos encontros cristãos nos fazem perceber o cotidiano, o dia a dia, a vida mais colorida! Quando nos damos conta dos variados matizes, o movimento das ruas, a 
mensagem evangélica assume um dinamismo que por vezes é perdido, ao estabelecermos estruturas fixas.

Ao nos utilizarmos da Hermenêutica dos Espaços, propomos inciar a leitura de um texto a partir de seus espaços, deslocando o olhar para o seu entorno imediato. Com isso, o ambiente, os relacionamentos, a dinâmica da vida parecem ir tomando forma, se intercalando e até interferindo na narrativa.

Cristãos e cristãs poderiam se reunir em vários espaços, a fim de celebrar a fé em Jesus, celebrar o ritual eucarístico enquanto partilhavam uma refeição comunitária. Em uma sociedade comunitária, a vida caminhava dessa forma, onde o grupo definia o indivíduo e não o contrário. Assim, o estar juntos era algo central na dinâmica da vida e, consequentemente, da vida cristã.

Ao percebermos os inúmeros espaços para esses encontros, também podemos perceber o hibridismo dos mesmos, quer dizer, um mesmo espaço poderia ser utilizado para várias coisas. Isso não o descaracterizava, muito pelo contrário, indicava a pluralidade e a diversidade presentes nesse e em todos os tempos.

\section{Referências bibliográficas}

ADAMS, Edward. The earliest Christian meeting places. Almost exclusively houses? Revised edition. London: Bloomsbury, 2016.

BALCK, David L. Rich Pompeiian houses, shops for rent, and the huge apartment building in Herculaneum as typical spaces for Pauline House Churches. Journal for the Study of the New Testament, Sheffield, v. 27, n. 1, p. 27-46, 2004.

BEARD, Mary. Pompeia: a vida de uma cidade romana. Trad. Cristina Cavalcanti. Rio de Janeiro: Record, 2016.

BRANICK, Vincent. A Igreja doméstica nos escritos de Paulo. São Paulo: Paulus, 1994.

BUSTAMANTE, Regina Maria da C. Em torno da mesa da elite na Roma antiga. Caliope: Presença Clássica. Rio de Janeiro, v. 11, n. 7-8, p. 95-111, 2003.

CIANCA, Jenn. Sacred ritual, profane space: the Roman house as early Christian meeting place. Montreal: McGill-Queen’s University Press, 2018.

COUlAngES, Fustel de. A cidade antiga. São Paulo: Martin Claret, 2007.

FRIESEN, Steven J. Poverty in Pauline studies: beyond the so-called New Consensus. Journal for the Study of the New Testament, Sheffield, v. 26, n. 3, p. 323-361, 2004.

FRIESEN, Steven J. Prospects for a demography of the Pauline Mission: Corinth among the Churches. In:SCHOWALTER, Daniel N.; FRIESEN, Steven J. (eds.). Urban religion in Roman Corinth: interdisciplinary approaches. Cambridge: Harvard Theological Studies 53, 2005.

HIRATA, Elaine Farias Veloso. Monumentalidade e representação do poder de uma pólis colonial. In: FLORENZANO, Maria Beatriz Borba; HIRATA, Elaine Farias Veloso (org.). 
Estudos sobre a cidade antiga. São Paulo: Editora da Universidade de São Paulo; Fapesp, 2009, p. 121-136.

HORREL, David G. Domestic space and Christian meetings at Corinth: imagining new contexts and the buildings East of the theatre. Journal for the Study of the New Testament, Sheffield, v. 50, p. 349-369.

KORMIKIARI, Maria Cristina Nicolau. O conceito de "cidade" no mundo antigo e seu significado para o norte da África Berbere. In: FLORENZANO, Maria Beatriz Borba; HIRATA, Elaine Farias Veloso (org.). Estudos sobre a cidade antiga. São Paulo: Editora da Universidade de São Paulo; Fapesp, 2009, p. 137-172.

O'CONNOR MURPHY, Jerome. St. Paul's Corinth: texts and archaeology. 3. revised and expanded edition. Collegeville, Minn.: Liturgical Press, 2002.

THEISSEN, Gerd. The social setting of Pauline Christianity. Philadelphia: Fortress Press, 1982.

WALLACE-HADRILL, Andrew. Houses and society in Pompeii and Herculaneum. Princeton: Princeton Universtiy Press, 1994. 